\title{
O jovem Machado de Assis e seus Comentários [afiados] da Semana
}

\author{
Cristiane da Silva Alves*
}

\begin{abstract}
Resumo: O presente artigo analisa as crônicas Comentários da Semana, de Machado de Assis. Examina-se, inicialmente, algumas características da crônica como gênero literário, especialmente a brevidade e a ligação com o cotidiano. O foco do trabalho consiste em observar as dificuldades do jovem Machado em suas crônicas iniciais e sua relação com a escrita e com os leitores.
\end{abstract}

Palavras-chave: Machado de Assis; crônica; Comentários da Semana

\begin{abstract}
This article analyzes the chronics Comentários da Semana, by Machado de Assis. It examines, initially, some characteristics of the chronic as literary genre, especially the brevity and the connection with the quotidian. The work focuses on observe the young Machado difficulties in his initial chronics and his relation with the writing and the readers.
\end{abstract}

Keywords: Machado de Assis; chronic; Comentários da Semana

Já que o próprio Machado sugeriu que a crônica nasceu, provavelmente, do comentário de duas vizinhas ${ }^{1}$, tomo a liberdade de apropriar-me de sua alegoria e, no intuito de melhor entender o cronista, pretendo analisá-lo sob a forma do "terceiro vizinho" que, tendo escutado a conversa das duas primeiras, não se conteve e deu a sua própria contribuição (apimentada, por certo). Assim, com o ar descompromissado de quem apenas reproduz os boatos circundantes, Machado trazia a lume as "quinquilharias" do cotidiano, unindo "o útil ao fútil", aparentemente para entreter a "gente miúda", mas que, no fim das contas, era, não rara vezes, um subterfúgio para denunciar movimentos da "gente graúda", nem sempre favoráveis à população, e que bem poderiam passar despercebidos e incólumes, não fosse a sagacidade de Machadinho. Pretende-se, pois, analisar algumas de suas crônicas e verificar, em Comentários da Semana, como atua o "terceiro vizinho" Machado, combinando bailes, teatro, literatura e política, tecidos todos no mesmo pano.

\footnotetext{
* Mestranda do Programa de Pós Graduação em Letras da Universidade Federal do Rio Grande do Sul na área de Estudos da Literatura, Especialidade: Literatura Brasileira. Licenciada em Letras - Português/Inglês pela mesma instituição.

1 "Não posso dizer positivamente em que ano nasceu a crônica; mas há toda a probabilidade de crer que foi coetânea das primeiras duas vizinhas. Essas vizinhas, entre o jantar e a merenda, sentaram-se à porta, para debicar os sucessos do dia. Provavelmente começaram a lastimar-se do calor. Uma dizia que não pudera comer ao jantar, outra que tinha a camisa mais ensopada do que as ervas que comera. Passar das ervas às plantações do morador fronteiro, e logo às tropelias amatórias do dito morador, e ao resto, era a coisa mais fácil, natural e possível do mundo. Eis a origem da crônica" (ASSIS, Machado. Histórias de quinze dias. Publicado em $1^{\circ}$ de novembro de 1877).
} 
Inicialmente, analisemos a crônica, como gênero literário, tomando emprestada a lição de Antônio Cândido, no ensaio que introduziu o $5^{\circ}$ volume da série Para Gostar de Ler: crônicas, aponta algumas de suas características, entre elas a despretensão e a proximidade com o dia-a-dia, o que explica a possibilidade desse gênero literário estar, como assinala o autor, "sempre ajudando a estabelecer ou restabelecer a dimensão das coisas e das pessoas. Em lugar de oferecer um cenário excelso, numa revoada de adjetivos e períodos candentes, pega o miúdo e mostra nele uma grandeza, uma beleza ou uma singularidade insuspeitadas" (CANDIDO, 1992, p. 13).

Igualmente, afirma Cândido (1992, p. 13) que a crônica "não tem pretensões a durar", eis que abrigada no jornal, "veículo transitório" do qual os escritores se valem sem a intenção de perpetuar a sua "obra" e manter apreço e prestígio por gerações.

Em que pese, todavia, ser a crônica esse tipo de texto caracterizado pela transitoriedade, pela efemeridade, no caso de Machado de Assis, especialmente, é possível nos surpreendermos com algumas de suas crônicas que se mostram, ainda hoje, interessantes e com temas absolutamente pertinentes às "atuais" mazelas e contradições de nosso país.

Em nosso país a vulgaridade é um título, a mediocridade um brasão; para os que têm a fortuna de não se alarem além de uma esfera comum é que nos fornos do Estado se coze e tosta o apetitoso pão-de-ló, que é depois repartido por eles, para glória de Deus e da pátria. Vai nisto um sentimento de caridade, ou, direi mesmo, um princípio de equidade e de justiça. Por toda a parte cabem as regalias ás inteligências que se aferem por um padrão superior; é bem que os que se não acham neste caso tenham o seu quinhão em qualquer ponto da terra. E dão-lhe grosso e suculento, a bem de se lhes pagar as injúrias recebidas da civilização. (Diário do Rio de Janeiro, 01 de novembro de 1861).

Embora colaborasse já há um certo tempo com alguns jornais e revistas cariocas ${ }^{2}$, e tivesse ingressado no Diário do Rio de Janeiro em 1860, é em outubro de 1861, quando contava com 22 anos, que Machado de Assis recebe o encargo de uma crônica fixa, passando a redigir os Comentários da Semana, cuja escrita seria interrompida em abril de 1862, retornando uma vez mais em 5 de maio do mesmo ano, quando sua seção foi definitivamente suspensa, devido, ao que tudo indica, às duras críticas ao governo, em desacordo com a orientação política adotada pelo jornal, versão que é sustentada por Jean- Michel Massa:

O diretor político do jornal, Joaquim Saldanha Marinho, verificara que Machado de Assis tinha a pena demasiadamente afiada. Sem dúvida, não se julgou que comentasse "inocentemente" as ocorrências notáveis de cada semana". Tôdas as verdades eram boas enquanto os liberais se encontravam na oposição. No decurso de 1862 desenhou-se para os liberais a oportunidade de

\footnotetext{
2 Já em 1855, com apenas 16 anos, Machado iniciara suas colaborações literárias, com algumas poesias publicadas na Marmota Fluminense, veículo para o qual, posteriormente, colaborou com traduções e críticas literárias. Também colaborou para o Correio Mercantil (1858, 1859), para o Jornal do Comércio (1858), para o Paraíba (1859), para o Espelho (1859, 1860) e para a Semana Ilustrada (1860), entre outros.
} 
participar do govêrno. Talvez fôsse preciso mostrar que o grupo não era composto de exaltados, mas sim de homens capazes de assumir o poder. (MASSA, 1971, p. 308).

Não há confirmação, todavia, de que Machado tenha sido, de fato, censurado. Há indícios e especulações sobre o assunto, mas provas evidentes não há. Lúcia Granja e Jefferson Cano, afirmam, a propósito, que

[...] se o cronista tivesse enfrentado realmente a censura política às suas opiniões, ela poderia ter começado já em janeiro de 1862, mas não há elementos bastantes para afirma-lo. De concreto, sabemos que a crônica desde então foi se espaçando, voltou aos ataques veementes ao governo por ocasião da inauguração de d. Pedro I e reapareceu, curta, em 5 de maio de 1862, anunciando que voltava para ficar, mas desaparecendo então para sempre. (GRANJA; CANO, 2008, p.19)

Inegável é que as crônicas realmente começaram a espaçar-se já em janeiro de 1862, quando, após os Comentários do dia 7, seguidos pelos do dia 14, seria de se esperar que novos Comentários sobreviessem no dia 21 de janeiro, o que não ocorreu. Quando retornou a sua seção, aliás, as palavras do próprio Machado parecem sugerir que "forças maiores" haviam lhe tolhido a escrita:

Começo retificando: devia dizer comentários da quinzena e não da semana. Com efeito, pela primeira vez em minha vida de cronista deixei passar uma semana sem vir dar aos leitores a minha opinião acerca das ocorrências dela.

Razões que não podem ser devassadas, e que me tocam particularmente, ocasionaram esta falta de dever. (Diário do Rio de Janeiro, 26 de janeiro de 1862).

Igualmente, no Comentário de 5 de maio de 1862, que seria o último, Machado inicia justamente abordando (ou seria queixando-se sobre?) a interrompida regularidade de suas publicações, mais uma vez sem especificar o motivo, que, todavia, não parece ter sido a própria vontade ou uma necessidade pessoal:

O que queria dizer, e que tão mal encabecei, era que havia há tempos uma revista semanal que eu publicava mais ou menos regularmente, comentando inocentemente as ocorrências notáveis de cada semana.

Motivos que não entram no domínio do público interromperam por longas semanas a publicação dos Comentários que de novo tomo e por cuja regularidade respondo. (Diário do Rio de Janeiro, 05 de maio de 1862).

O que realmente teria acontecido, não o sabe a crítica. O que se sabe verdadeiramente é que, ao contrário do que sustenta o autor, seus Comentários não eram exatamente o que se possa chamar "inocentes". Mordaz e audacioso, o jovem Machado ainda não dominava a arte da dissimulação que viria a consagrá-lo em sua maturidade e lançava-se à peleja sem maiores cuidados, denunciando, agredindo, "duelando" através de sua "afiada pena" sempre que algo ou alguém lhe desagradava. "Sou um pouco audaz nas minhas investigações", afirmava, "e 
não poucas vezes tenho visto que a audácia acaba muitas vezes por dar na cabeça, bem que em alguns casos seja uma virtude preciosa" (Diário do Rio de Janeiro, 14 de janeiro de 1862).

Em meio aos seus "inocentes" Comentários acerca de bailes, teatro, e assuntos de cunho literário envolvendo a semana, Machado reservava sempre um bom espaço para os destaques políticos, onde não poupava críticas e tampouco alvos, fossem eles ministros, imperadores ou meros desafetos. "Duelava” pelos e até mesmo com amigos, se entendesse necessário. Assim teria, a propósito, justificado-se a um amigo de cujas notas discordava: "[...] tenho-te dado sobejas provas de que não costumo subordinar as minhas opiniões ao interesse ou conveniências, e que, errôneas ou verdadeiras, são-me elas sempre ditadas pela consciência" (Diário do Rio de Janeiro, 8 de fevereiro de 1862).

Se aos próprios amigos Machado não poupava, quando os entendia em desacordo com a verdade e a justiça, maiores e mais agudas farpas reservava aos desafetos, entre os quais, ao que tudo indica, o seu "predileto" era o colaborador do Jornal do Comércio, Scoevola:

Nas colunas do "Jornal do Comércio" continuam a aparecer os contendores da questão diplomática. "Scoevola", depois de ter feito sacrifício da mão direita diante de Porsena, anda mostrando que é capaz ainda de outras coisas muito mais asseadas. (Diário do Rio de Janeiro, 24 de dezembro de 1861).

Este incidente da conversa com o presidente Lopez tira-me o prazer de ocupar-me um pouco com o Scoevola, a respeito do interesse que S. S. está tomando pela sorte das repúblicas vizinhas, tornando-se até procurador das Altezas em disponibilidade. (Diário do Rio de Janeiro, 29 de dezembro de 1861).

Um dia antes Scoevola havia começado uma série de artigos sobre o casamento da princesa imperial, prometendo discorrer para diante, acerca da conveniência de diversos partidos de casamento, que possam oferecer à herdeira da coroa brasileira. Até agora, nada.

Pois é pena! Estava divertido com os seus protestos de queimar a mão, e com as mesuras repetidas que fazia diante do augusto assunto de que tratava. A mim, se me afigurou ver o cabeçalho de um Manual de civilidade cortesã. (Diário do Rio de Janeiro, 07 de janeiro de 1862).

O jornalista era, como se pode notar, alvo constante da pena de Machado, que não cansava de "cutucar-lhe", ora com ferocidade, ora com ar de moleque debochado, atrevido e implicante, como se observa em um dos seus últimos ataques, talvez o mais contundente:

O publicista casamenteiro não é das coisas que menos riso excitam; pelo contrário, é divertido a mais não poder.

Já declarou que não quer ser mordomo do novo rei, nem aspira a ser senador no Estado criado por ele próprio; mas já me parece generosidade de mais, isto de fazer monarquias pelo simples e honestíssimo prazer de ver a realeza aliada à liberdade.

$[\ldots]$

Assim, cheguei a pensar que Scoevola queria tirar desta solicitude pelas augustas princesas e pelos Estados do Prata as vantagens a que visam todos aqueles que só vêem este mundo pelo ponto de vista das armarias heráldicas.

A declaração em contrário de Scoevola em seu último escrito avulta tanto como um caracol. Scoevola, pelos modos, pertence a certo partido político que não tem sacrificado muito à sinceridade, e tem como regra de diplomata que a palavra foi dada ao homem para esconder os conceitos e as convicções. 
Terá ele lido no futuro que a forma monárquica há de vir a estabelecer-se no Rio da Prata, e quererá desde já mostrar-se o propugnador extremoso dessa idéia, que considera a única salvadora daquelas repúblicas? A sua vaidade far-lhe-á ver-se desde já vazado em bronze a figurar no meio de uma praça do novo reino?

Este meio de perpetuidade alcança longe e alto demais para supô-lo no espírito de Scoevola.

Opto pela primeira impressão.

$[\ldots]$

Scoevola tem a boca doce. Pertence a um partido que não cochila quando quer fazer triunfar (sabe o país por que meios) uma conveniência; mas ilude-se quando supõe que a opinião argentina há de fazer sacrifício da sua independência. Os Vera-Cruzes são raros. (Diário do Rio de Janeiro, 14 de janeiro de 1862).

Outro alvo constante da "pena afiada" de Machado era o gabinete ministerial, em cujas críticas se pode perceber o engajamento do jovem autor e o seu empenho em trazer a lume quaisquer atos duvidosos, em especial os favorecimentos secretos, à revelia da lei e em prejuízo dos interesses do povo, como no caso do Sr. Candido Borges, a quem teria o governo aposentado antes de se completar o tempo de serviço, fato contra o qual se insurgiu Machado publicamente, forçando o governo a explicar-se. Nem mesmo a resposta do governo, contudo, apaziguou o ânimo do escritor que, irônico, insistiu ainda no tema, apresentando nos Comentários seguintes a sua "réplica":

Veio o governo em respostas ao dizer do boato, que eu denunciei nos últimos Comentários, e declarou o Diário em completa ignorância dos fatos a que aludi.

Devo observar que apenas fui eco de um boato, e que foi com uma franqueza e uma singeleza talvez proverbiais que transferi para letra redonda o que andava na praça pública, pedindo ao governo uma explicação que restabelecesse a verdade.

O comunicante oficial declarou desconhecer a importância da censura que corria pela boca pequena em detrimento do crédito do governo. Sem dúvida que não é problema social ou político, não se trata da questão da escravidão ou de qualquer outra de máximo alcance; mas presumo que a acusação surda ao governo de uma infração da lei não é lá tão ínfima assim que mereça escárnio e o pouco caso da imprensa.

Dizia-se isto; a imprensa pergunta ao governo se isto é verdade. Creio que é a coisa mais curial do mundo.

Explicou-se o governo, ainda bem. Da explicação se conclui que o boato não era tão inteiramente infundado como se quis fazer supor; houve de fato uma pequena acumulação, ou antes, pretendeu-se realizá-la. (Diário do Rio de Janeiro, 14 de janeiro de 1862).

Não se sabe, como foi dito anteriormente, se Machado sofreu alguma espécie de censura, mas, coincidência ou não, após o seu revide ao governo, os Comentários só retornaram no dia 26 de janeiro, ou seja, com um intervalo de quase duas semanas, nem por isso abrandando os arroubos de "Machadinho" que voltou a praticar a sua "arte", dessa vez alfinetando o Presidente da província do Rio de Janeiro e uma portaria sua que, como informa Machado, ocupava-se, de forma inacreditável, da questão de "dúvidas suscitadas por um sino sem badalo", questão ridícula e de seriedade discutível, como insinua o cronista:

Na dúvida de quem havia de tanger o sino a recolher, S. Excia. Tomou o partido de incumbir isso ao sacristão ou a outro qualquer empregado da igreja. 


\section{$[\ldots]$}

Algum observador aparentado com Demócrito poderá achar razão nestas bernardices administrativas, invocando o princípio dos contrapesos e das compensações, e assim dizer que em país tão grande, territorialmente falando, como este, é bem que a direção das coisas públicas apresente este aspecto de ninharias e ridiculidades, a fim de estabelecer o alto e malo das coisas humanas...

Deixo aos filósofos a discussão deste dito.

$[\ldots]$

Passarei agora a coisas sérias. (Diário do Rio de Janeiro, 26 de janeiro de 1862).

Se não se pode comprovar a censura, não se pode, da mesma forma, ignorar a inexplicável irregularidade com que viriam a público os próximos Comentários, com um espaço de tempo cada vez maior a separar-lhes, senão vejamos: em 08 e 22 de fevereiro, 02 e 24 de março, $1^{\circ}$ de abril e, finalmente, 05 de maio de 1862, quando cessavam em definitivo. Como bem explica Jean-Michel Massa, "a imprensa era livre. É notório o fato e Machado de Assis também se apercebeu da coisa. Contudo, esta liberdade, paradoxalmente, era menor no jornal em que colaborava do que no país" (MASSA, 1971, p. 304).

Assim, é impossível não notar, por exemplo, que na crônica de 2 de março a "pena afiada" encontrava-se um tanto quanto tímida, limitando-se a comentários de cunho teatral e literário, em lugar dos acirrados embates políticos com que se ocupara por largo tempo. $\mathrm{O}$ jovem idealista, ao menos aparentemente, cedera ao cansaço e ao descontentamento, ocupando-se, daí por diante, quase que exclusivamente de assuntos literários. "O malôgro que sentiu", conforme afirma Jean-Michel Massa, "se explica por uma inadaptação a êsses jogos sutis, nascida da sua juvenil intransigência. Êste insucesso levou-o a procurar na literatura, menos impura, senão outras satisfações, pelo menos outro caminho" (MASSA, 1971, p. 310).

O que teria realmente acontecido, escapa à crítica. De concreto, sabe-se apenas que, embora jovem, Machado já gozava de notável talento, que não era ainda o que lhe consagraria como o "grande" Machado, posteriormente, mas que já possibilitava, nos Comentários, antever a sagacidade e ousadia do autor, sempre atento às questões de seu tempo, trazendo à tona a "matéria escondida", desvelando o reles, oculto sob a aparência de sublime e, de certa forma, tornando-o sublime de fato, através de sua pena.

É forçoso ressaltar que, ao dizer que o autor não era ainda o "grande" Machado, não é com o intuito de desmerecer o jovem, mas tão somente porque é inegável a timidez do estilo e da escrita nessas suas publicações iniciais. Machado tinha muito a dizer e muito espírito para fazê-lo, mas padecia ainda de algumas dificuldades técnicas no manejo da pena, especialmente no que tange à "costura" dos temas em suas crônicas que, não raras vezes, sofriam passagens bruscas e artificiais de um assunto a outro. 
As dificuldades iniciais da escritura, a propósito, eram confirmadas pelo próprio Machado que, vez ou outra, queixava-se ao leitor, como se pode perceber, por exemplo, nos seus Comentários de $1^{\circ}$ de dezembro de 1861: "Esta linha de pontinhos indica que vou passar a assuntos de outro gênero, para os quais não achei uma transição capaz". O mesmo recurso a linha de pontinhos - seria utilizado novamente em 24 de dezembro de 1861, logo após comentar a morte do amigo Paula Brito, tipógrafo e editor, diretor da Marmota Fluminense.

Outro problema aventado pelo cronista era a dificuldade e necessidade de obter notícias "frescas" a fim de satisfazer o insaciável público leitor, sempre à espera de novidades, como aponta Machado, não sem uma certa dose de sarcasmo, em sua crônica datada de 7 de janeiro de 1862:

Bem se podia comparar o público àquela serpente - deus dos antigos mexicanos - que, depois de devorar um alentado mamífero, prostra-se até que a ação digestiva lhe tenha esvaziado o estômago; então o flagelo das matas corre em busca de novo repasto, emborca novo animal pela garganta abaixo e cai em nova e profunda modorra de digestão.

Esquisita que pareça a comparação, o público é assim. Precisa de uma novidade e de uma grande novidade; quando lhe aparece alguma, digere-a com placidez e calma, até que desfeita ela, outra lhe fica ao alcance e lhe satisfaz a necessidade imperiosa. (Diário do Rio de Janeiro, 7 de janeiro de 1862).

Essa necessidade de satisfazer o público, aliás, seria igualmente afirmada por Bilac, que sucedeu Machado na crônica de domingo da Gazeta de Notícias e assim explicava o seu padecimento: "Um cronista vive sempre no apuro dos empresários que, tendo pouco pessoal e pouco dinheiro, têm de servir ao público peças de grande espetáculo, exigindo volumosas massas corais e movimento extraordinário de comparsaria" (BILAC, apud CHALHOUB, 2005, p. 15).

Machado, por sua vez, falseando modéstia, mostra-se humilde diante do leitor, ressaltando a constante e difícil busca por novidades com que ilustrar os seus Comentários, explicando ainda o quão vexatório e inadmissível era para ele apresentar-se diante do público sem novas notas:

Acreditando que o leitor me procura por desfastio, não ousando pensar que inspiro avidez ou curiosidade, acho-me sinceramente vexado quando apareço de alforge vazio, e mais vazia a alma, de com que entreter os ócios do leitor.

Creio que faço o meu efeito de um touriste ao voltar do Oriente, sem uma nota, sem um desenho, na sua caderneta de viagem. Tão impossível parece voltar das regiões do berço do sol, sem uma impressão, com o atravessar sete dias sem haver colhido uma notícia para comentar.

Pois a última hipótese não é nenhuma coisa de admitir.

É de se notar que as agruras apontadas em suas crônicas não se davam em razão da pouca idade ou de uma certa inexperiência, mas, principalmente, motivadas por dificuldades inerentes ao próprio gênero literário, porquanto, vinculado à cotidianidade e ao seu 
movimento, escapa muitas vezes ao domínio do cronista, por mais experimentado que seja. Nesse aspecto, Sidney Chalhoub cuida de demonstrar que

ainda que possa caracterizar o ponto de vista da narração, os objetivos da série e o campo temático das discussões que deseja implementar, o cronista está sempre sujeito ao impoderável do cotidiano, que tanto lhe fornece temas e problemas com os quais discutir quanto modifica e redireciona suas opções iniciais. (CHALHOUB, 2005, p. 15)

Não por acaso, padecendo dos mesmos males, Olavo Bilac também viria a queixar-se do "martírio de quem é obrigado a escrever sempre cousas novas sobre semanas que se parecem com irmãs gêmeas" (BILAC, apud CHALHOUB, 2005, p. 15).

Com efeito, carecia o cronista de verdadeiros malabarismos para ter com o que "entreter" os leitores, especialmente quando o cenário, longe de ser propício, apresentava-se desprovido de fatos novos ou, ao menos, interessantes. Por vezes, nada havia de relevante que merecesse gastar-lhe a pena, deixando o escritor, como dizia Machado, de "alforge vazio", o que só mesmo a destreza era capaz de contornar. Entrava em jogo, então, a habilidade do cronista para trabalhar a massa miúda e, com o fermento do humor, da ironia e da perspicácia, formar o grande bolo que havia de alimentar o público leitor, ainda que por um breve momento. Nesse jogo, contudo, de apropriar-se da "cousa miúda" e torná-la consistente, "Machadinho", desde cedo, era mestre, tendo logo percebido "a liga do "útil e do fútil" que fazia a sua graça", como diz Arrigucci Jr. (1987, p. 58).

E pôs mãos à obra, dedicando-se a uma espécie de prática de relativização dos solavancos entre os altos e baixos do assunto; balanceando, com distanciamento irônico, os pesos e contrapesos de toda questão. A cada momento puxa a vida do espírito para baixo, para o chão material e, ao mesmo tempo, se entrega, com prazer perverso, a uma metafísica de quinquilharias. Todo grande acontecimento com ar usurpador pode ser despachado com um piparote em benefício de uma "pobre ocorrência de nada". De uma penada se esvaziam linhas gordas de objetos inúteis, mas parece que há sempre novas prateleiras vazias no espírito, aguardando outros tantos. Tudo isso feito minuciosamente, com capricho e fleuma, conforme um senso ferino de humor, que tem também seu contrapeso de delírio. (ARRIGUCCI JR., 1987, p. 58)

Embora se prefira, muitas vezes, creditar a notoriedade de Machado a uma espécie de genialidade ou capacidade metafísica, é necessário destacar que a sua obra deve muito mais ao empenho, à dedicação, ao trabalho árduo e constante, que moldou, paulatinamente, o "grande" Machado, como nós o conhecemos. O escritor, sobretudo, era atento, ousado, e sabia manejar a sua pena com graciosidade, extraindo o sumo da "matéria miúda", lapidando-o até se tornar precioso, sublime. É assim que, como lembra Arrigucci Jr.,

se afina pelo tom menor que será, daí para a frente, o da crônica brasileira, voltada para as miudezas do cotidiano, onde acha a graça espontânea do povo, as fraturas expostas da vida social, a finura dos perfis psicológicos, o quadro de costumes, o ridículo de cada dia e até a poesia mais alta que ela chega alcançar, como em tantas de Rubem Braga. (ARRIGUCCI JR., 1987, p. 59) 
Se suas crônicas iniciais não eram, como bem o sabemos, obras-primas, é forçoso, todavia, que sejam valorizadas. Afinal, através de seus Comentários da Semana, o jovem Machado, o brigão "Machadinho", afiava a sua pena, deixava a sua marca, e dava lugar, pouco a pouco, ao grande, sagaz, e irônico Machado de Assis, mestre na arte de dissimular, de ocultar intenções, dizendo, sem dizer, no entanto, o que pensava.

Se Machado pareceu, com o passar dos anos, menos engajado e comprometido, não nos enganemos: ele cuidava apenas de não mais se lançar à peleja dominado pelos arroubos da juventude e sim com arte e cuidado, com o refinamento adquirido pelos anos e pela experiência no manejo da pena que, seguramente, tornou-o mais sábio, mas não menos audacioso. Passados os primeiros anos, superadas as dificuldades iniciais, as crônicas de Machado se afiaram ainda mais, revestindo-se, todavia, da máscara irônica e dissimulada que ele viria a apurar ao longo dos anos, obrigando o leitor a procurar nas entrelinhas até trazer à tona aquilo que se encontrava por detrás das aparências, a matéria que não se manifestava à primeira vista. O processo engendrado e aperfeiçoado por Machado - e nisso reside sua arte não mostrava diretamente, mas insinuava, induzia, gentilmente convidava o leitor a abandonar a ingenuidade e decifrar o que não estava dito, embora posto, desconfiando do texto e das suas intenções. Somente após ultrapassar a superfície do texto, aliás, imergindo em sua essência, poderia o leitor compreender e fruir o verdadeiro discurso de Machado, aquilo que de fato ele almejava revelar.

Não apenas o que estava dito, pois, mas - e principalmente - o que se encontrava oculto, constituiria a matéria de suas crônicas. Sob a escrita aparentemente leve e despretensiosa, o cronista havia de expor ao longo dos anos, entre ironias e gracejos, as mazelas do país e da sociedade. O mais interessante é que, embora o foco de Machado fosse o Rio de Janeiro de seu tempo, as questões por ele expostas podem aplicar-se a qualquer outro espaço/tempo, eis que nelas estão reunidas, principalmente, questões de ordem humana, social e cultural. Se em sua aparência as crônicas machadianas guardam a aparência da fugacidade, tratando apenas de amenidades e/ou banalidades cotidianas, em seu interior descortina-se diante do leitor um panorama da sociedade em seu cerne, para além dos bailes e exposições.

\section{Referências}

ARRIGUCCI JR., Davi. Fragmentos sobre a crônica. In: das Letras, 1987. . Enigma e Comentário. São Paulo: Companhia 
ASSIS, Machado de. Comentários da Semana. Org. Lucia Granja; Jefferson Cano. Campinas, Ed. Unicamp, 2008.

ASSIS, Machado de. Obra Completa. Rio de Janeiro: Edições W. M. Jackson,1938. Disponível em http://portal.mec.gov.br/machado. Acesso em 22 de março de 2009.

CÂNDIDO, Antonio. A vida ao rés-do-chão. In: A Crônica: o gênero, sua fixação e suas transformações no Brasil. Campinas, SP: Editora da Unicamp, 1992.

CHALHOUB, Sidney et al. História em cousas miúdas:capítulos de história social da crônica no Brasil. Campinas, SP: Editora da Unicamp, 2005.

MASSA, Jean-Michel. A juventude de Machado de Assis (1839-1870). Tradução de Marco Aurélio de Moura Matos. Rio de Janeiro: Civilização Brasileira, 1971. 